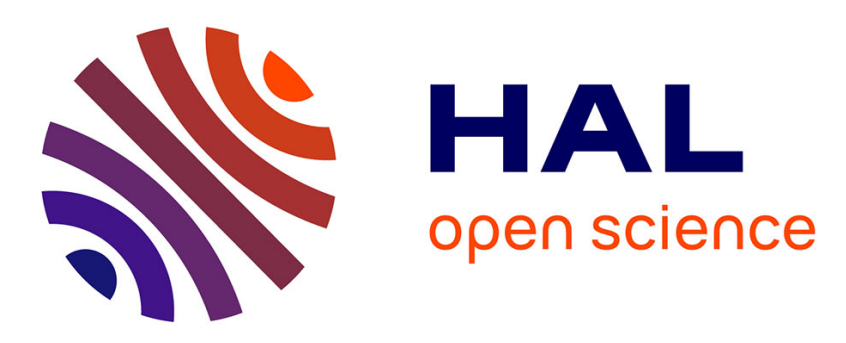

\title{
Electrochemical Reduction Prior to Electro-Fenton Oxidation of Azo Dyes: Impact of the Pretreatment on Biodegradability.
}

Florence Fourcade, Mathieu Delawarde, Laurence Guihard, Stéphane Nicolas, Abdeltif Amrane

\section{To cite this version:}

Florence Fourcade, Mathieu Delawarde, Laurence Guihard, Stéphane Nicolas, Abdeltif Amrane. Electrochemical Reduction Prior to Electro-Fenton Oxidation of Azo Dyes: Impact of the Pretreatment on Biodegradability.. Water, Air, and Soil Pollution, 2013, 224 (1), pp.1385. 10.1007/s11270-0121385-0 . hal-00809486

\section{HAL Id: hal-00809486 https://hal.science/hal-00809486}

Submitted on 10 Dec 2013

HAL is a multi-disciplinary open access archive for the deposit and dissemination of scientific research documents, whether they are published or not. The documents may come from teaching and research institutions in France or abroad, or from public or private research centers.
L'archive ouverte pluridisciplinaire HAL, est destinée au dépôt et à la diffusion de documents scientifiques de niveau recherche, publiés ou non, émanant des établissements d'enseignement et de recherche français ou étrangers, des laboratoires publics ou privés. 


\title{
ELECTROCHEMICAL REDUCTION PRIOR TO ELECTRO-FENTON OXIDATION OF AZO DYES. IMPACT OF THE PRE-TREATMENT ON BIODEGRADABILITY
}

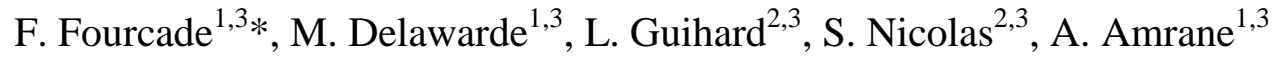

\author{
${ }^{1}$ Université Rennes 1, CNRS, UMR 6226, Avenue du Général Leclerc, CS 50837, 35708 \\ Rennes Cedex 7, France \\ ${ }^{2}$ Université de Rennes 1, Département Chimie, IUT de Rennes, 3 rue du Clos Courtel, BP \\ 1144, 35014 Rennes Cedex, France \\ ${ }^{3}$ Université européenne de Bretagne \\ *Phone: (+33) 2232381 58; Fax: (+33) 2232381 20; \\ florence.fourcade@univ-rennes1.fr
}

\begin{abstract}
The aim of this work was to study the degradation of three azo dyes, Orange II, Methyl red and Biebrich Scarlet by electro-Fenton and the effect of the electrochemical pre-treatment on the biodegradability of the solutions.

The electrochemical pre-treatment showed that an electrochemical reduction on the carbon felt electrode was mainly responsible for the decolorization of the azo dyes. Indeed, the electrochemical behaviour of the azo dyes highlighted their electroactivity, electrolysis with and without ferric ions led to the same decolorization yield, namely $99 \%$ at 15 min for Methyl red, and stable COD values were recorded during decolorization. In a second step and owing to the absence of by-products electroactivity in reduction, the formation of hydroxyl radicals
\end{abstract}


by the Fenton reaction led to the oxidation of by-products from the electrochemical reduction. It was illustrated by the decrease recorded for the COD values.

The results also showed that the azo bond cleavage occurring during the electrochemical reduction was not sufficient to significantly reduce recalcitrance as shown from $\mathrm{BOD}_{5} / \mathrm{COD}$ ratio examination below the limit of biodegradability (0.4). Contrarily, a positive trend was recorded for Orange II during the electro-Fenton reaction, with a $\mathrm{BOD}_{5} / \mathrm{COD}$ ratio of 0.81 after $28 \mathrm{~h}$ of pre-treatment.

Keywords: Electro-Fenton; Electrochemical reduction; Azo dye; Biodegradability.

\section{Introduction}

Industrial wastewater purification is a matter of great interest for the scientific community. The problem is complex due to the wide variety of pollutants whether minerals or organics. Organic dyes constitute one of the largest groups of pollutants in wastewater. Among the 1,000,000 tons per year of dyes produced, about $60-70 \%$ are azo-dyes (Forgacs et al. 2004), and about $15 \%$ are released in the environment (E. Guivarch et al. 2003b). The discharge of highly coloured wastewater into the ecosystem involves environmental burdens. Due to their coloration, dyes cause floral and aesthetic pollutions (even a small amount of dye is clearly apparent). Some dyes are also potentially toxic, as well as their by-products such as aromatic amines (Dominguez et al. 2005; Arslan et al. 2000). They can also induce perturbations of aquatic life since some azo-dyes and degradation products are highly carcinogenic (Brown and De Vito 1993). 
Biological treatments, which are the most cost-effective and the most environmental friendly processes appear not recommended owing to the biorecalcitrance of azo dyes. Moreover, some metabolites such as aromatic amines produced during the cleavage of the azo bond are more toxic than the target compound (Tantak and Chaudhari 2006)

Physical techniques can be used to remove recalcitrant pollutants (Robinson et al. 2001; Auriol et al. 2006) but the main drawback is the need to quite costly regeneration and posttreatment processes, owing to the non destructive characteristic of these processes. Indeed, the pollutant is only transferred to another phase (Arslan et al. 2000; Chaudhuri and Sur 2000; Stock et al. 2000).

Contrarily, physico-chemical processes are destructive and are also widely used to remove recalcitrant compounds. Among these processes, Advanced Oxidation Processes (AOPs) appear as an interesting way for the treatment of the azo dyes pollution (Comninellis et al. 2008). They are based on the formation of easy produced, non selective and very reactive hydroxyl radicals (Oppenländer 2003; Chiron et al. 2000). The high reactivity of hydroxyl radical allows the oxidation of dyes into $\mathrm{CO}_{2}, \mathrm{H}_{2} \mathrm{O}$ and inorganic ions or biodegradable compounds (Hachem et al. 2001).

The electro-Fenton process is an indirect oxidation process. It is based on the continuous electro-generation of hydrogen peroxide in aqueous solution by dissolved oxygen reduction on a mercury, graphite felt or an oxygen-diffusion cathode (Hammami et al. 2008; Sires et al. 2008; Wang et al. 2005; Brillas et al. 2009) and/or ferrous ions (E. Guivarch et al. 2003a):

$\mathrm{O}_{2}+2 \mathrm{H}^{+}+2 \mathrm{e}^{-} \rightarrow \mathrm{H}_{2} \mathrm{O}_{2}$

$\mathrm{Fe} \rightarrow \mathrm{Fe}^{2+}+2 \mathrm{e}^{-}$

The Fenton reaction corresponds to the production of hydroxyl radicals ${ }^{\bullet} \mathrm{OH}$ from the reaction between $\mathrm{H}_{2} \mathrm{O}_{2}$ and ferrous ions $\mathrm{Fe}^{2+}$ : 
$\mathrm{Fe}^{2+}+\mathrm{H}_{2} \mathrm{O}_{2} \rightarrow \mathrm{Fe}^{3+}+\mathrm{OH}^{\circ}+\mathrm{OH}^{-}$

Electro-Fenton has been shown to be efficient for azo dyes removal (Daneshvar et al. 2008; Ozcan et al. 2008; Panizza and Cerisola 2009) and the in situ generation of $\mathrm{H}_{2} \mathrm{O}_{2}$ avoids the need for transport and storage of this hazardous substance (Rosales et al. 2009). ElectroFenton can be combined with other Advanced Oxidation Processes such as anodic oxidation (Borras et al. 2011), (Cruz-Gonzales et al. 2012) for a better production of hydroxyl radicals.

Due to a relatively high operational cost of AOP, potential advantage of the strategy of combining chemical and biological processes to treat contaminants in wastewater was previously suggested (Scott and Ollis 1995, 1997) (Oller et al. 2011). In this aim, integrated processes including either $\mathrm{UV} / \mathrm{H}_{2} \mathrm{O}_{2}$ or $\mathrm{UV} / \mathrm{O}_{3}$ (Ledakowicz et al. 2001) or photo-Fenton $\mathrm{UV} / \mathrm{Fe}^{3+} / \mathrm{H}_{2} \mathrm{O}_{2}$ (Dominguez et al. 2005) followed by biological treatment have been proposed to treat wastewater released by the textile industry.

AOP constitute a pretreatment in order to increase the biodegradability of the recalcitrant azo-dyes, leading to the formation of non toxic by-products, more readily metabolizable by microorganisms (De La Rochebrochard D'Auzay et al. 2007; Poyatos et al. 2010).

Previous studies on the relevance of coupling photocatalysis and a biological treatment showed that the biodegradability did not increase after total decolorization most likely due to a too low residual COD and thus a too low available organic carbon for the metabolism of microorganisms. Moreover some of the by-products were more toxic than the initial compound (Chebli et al. 2010).

In this study, the relevance of a pre-treatment based on the electro-Fenton process prior to biodegradation was studied for three azo-dyes degradation: Methyl Red, Biebrich Scarlett and Orange II. In the same time, the mechanism of azo dyes degradation was discussed. 


\section{Materials and Methods}

\subsection{Azo dyes}

Methyl Red (MR), Orange II (OR II) and Biebrich Scarlett (BS) were used without further purification, owing to their high purity, at least $99 \%$. Methyl red was used under its salt form owing to the high available purity. They were purchased from Sigma Aldrich (Isle d'Abeau Chesnes, France). Their molecular structures are given in Fig.1. Distilled water was used to prepare the coloured solutions.

\subsection{Material for electro-Fenton}

A three electrode system was used to carry out the electro-Fenton reaction in $400 \mathrm{~mL}$ of solution to be treated. All the potentials were measured with respect to a saturated calomel electrode located near the working electrode and immersed in a glass frit (porosity 5) containing $\mathrm{H}_{2} \mathrm{SO}_{4}$ solution at $\mathrm{pH}=1$. The working electrode was a graphite felt cathode with a geometrical surface of $74.5 \mathrm{~cm}^{2}$. Graphite felt was purchased from Le Carbone Lorraine (RVG 4000). Its specific area, measured by the BET method was $0.7 \mathrm{~m}^{2} \cdot \mathrm{g}^{-1}$; its density was $0.088 \mathrm{~g} . \mathrm{cm}^{-3}$ and its carbon yield was $99.9 \%$. A platinum counter electrode (area $31.4 \mathrm{~cm}^{2}$ ) was fitted into a separate compartment, in $\mathrm{H}_{2} \mathrm{SO}_{4}$ solution at $\mathrm{pH}=1$. The electrochemical apparatus was an EG\&G Princeton Applied Research model 363 Potentiostat/Galvanostat (AMETEK, Elancourt, France).

Throughout experiments, compressed air was bubbled in the working electrode compartment. A catalytic amount of ferric iron was introduced into the solution before the beginning of electrolysis. The solutions were magnetically stirred at $320 \mathrm{rpm}$, and the temperature was maintained at $30^{\circ} \mathrm{C}$ by means of a thermostated bath. 


\subsection{Material for voltammetric studies}

Current-potential curves were performed using three electrodes. The working electrode was a rotating vitreous carbon disk $(1500 \mathrm{rpm})$ with a surface of $7 \mathrm{~mm}^{2}$. A platinum wire was used as counter electrode and all the electrode potentials were measured with respect to a saturated calomel electrode (SCE). The experiments were performed in a $75 \mathrm{~cm}^{3}$ electrochemical cell at ambient temperature under nitrogen atmosphere.

The electrochemical apparatus was a Potenstisotat PGP 201 Voltalab (Radiometer Analytical, Villeurbanne, France) with voltamaster 4 software.

\subsection{Analyses}

At scheduled times, $5 \mathrm{~mL}$ of samples were taken from the reactor.

\section{Decolorization}

It was followed by means of a UV-Vis Thermospectronic Helios 8 spectrophotometer (Bioblock, Illkirch, France) at the maximum absorption wavelength or isobestic point (Chebli et al. 2010) (Table 1) for each considered dye.

\section{Chemical Oxygen Demand (COD) measurements}

It was measured by means of Nanocolor ${ }^{\circledR}$ CSB 40 and 160 tests from Macherey-Nagel (Düren, Germany). The amount of oxygen required for the oxidation of the organic and mineral matter at $148^{\circ} \mathrm{C}$ for $2 \mathrm{~h}$ was quantified after oxidation with $\mathrm{K}_{2} \mathrm{Cr}_{2} \mathrm{O}_{7}$ at acidic $\mathrm{pH}$ and heating.

\section{Biological oxygen demand $\left(\mathrm{BOD}_{5}\right)$ measurements}

Biological Oxygen Demand $\left(\mathrm{BOD}_{5}\right)$ measurements were carried out in an Oxitop IS6 (from WTW) in order to check the biodegradability of the effluent.

The same procedure was applied to inoculate samples, the blank solution and the control solution. The following mineral basis was used for all experiments $\left(\mathrm{g} . \mathrm{L}^{-1}\right)$ : $\mathrm{MgSO}_{4} .7 \mathrm{H}_{2} \mathrm{O}$, 22.5; $\mathrm{CaCl}_{2}, 27.5 ; \mathrm{FeCl}_{3}, 0.15 ; \mathrm{NH}_{4} \mathrm{Cl}, 2.0 ; \mathrm{Na}_{2} \mathrm{HPO}_{4}, 6.80 ; \mathrm{KH}_{2} \mathrm{PO}_{4}, 2.80$. 
The $\mathrm{BOD}_{5}$ value was initially estimated based on the COD value experimentally measured or calculated, $\mathrm{BOD}_{5}=\mathrm{COD} / 1.46$. The range of expected $\mathrm{BOD}_{5}$ measurement was then deduced and hence led to the volume of sample, the activated sludge solution $\left(0.5 \mathrm{~g} . \mathrm{L}^{-1}\right)$ and nitrification inhibitor (10 mg. $\mathrm{L}^{-1}$ solution of N-Allylthiourea) which have to be added in the shake flask of the Oxitop apparatus.

Similar protocol was applied for the control sample except that it was replaced by a solution of easily biodegradable compounds, namely glutamic acid (150 mg. $\left.\mathrm{L}^{-1}\right)$ and glucose (150 mg. $\left.\mathrm{L}^{-1}\right)$. Before use, $\mathrm{KOH}$ was added to achieve neutral $\mathrm{pH}(7.0 \pm 0.2)$. Similar protocol was also considered for the blank solution, for which the sample was replaced by water to have a negligible $\mathrm{BOD}_{5}$ value.

\section{Enzymatic determination of hydrogen peroxide}

It was based on the oxidation of reduced ABTS (2.2'-azino-bis(3-ethylbenzthiazoline-6 sulphonic acid) by hydrogen peroxide into oxidized ABTS. The reaction was catalysed by peroxidase (POD). Hydrogen peroxide was deduced from the determination of oxidized ABTS by spectrophotometry at $420 \mathrm{~nm}$ wavelength.

$\mathrm{H}_{2} \mathrm{O}_{2}+$ Reduced ABTS $\stackrel{P O D}{\longrightarrow} 2 \mathrm{H}_{2} \mathrm{O}+$ Oxidized ABTS

\section{Results and discussion}

\subsection{Electrochemical pretreatment}

\subsubsection{Electrochemical behavior of azo dyes}

The electrochemical behavior of azo dyes was examined and current potential curves were plotted for the three azo dyes with a vitreous carbon rotating disk electrode, under nitrogen atmosphere. The electroactivity of the three azo dyes was clearly highlighted in the figure 2 . For all dyes, a limiting current region was well defined and it was shown that each dye could be reduced at the electrode surface. 
A limiting current region was well defined from -0.3 and $+0.140 \mathrm{~V} / \mathrm{SCE}$ for OR II and MR, respectively (Figs. 2a and b). For BS, two limiting current regions were observed, the first from +0.130 to $+0.010 \mathrm{~V} / \mathrm{SCE}$ and for the second plateau from +0.010 to around -0.8 V/SCE (Fig. 2c).

At -0.4 and $-0.5 \mathrm{~V} / \mathrm{SCE}$ corresponded a limiting current of $-20 \mu \mathrm{A}$ and $-27 \mu \mathrm{A}$ for $\mathrm{MR}$ and OR II, respectively (Figs. 2b and 2a).

These signals could not be attributed to the reduction of dissolved dioxygen as suggested by Daneshvar et al. (Daneshvar et al. 2008) because in the operating conditions, dioxygen was removed from the solution by nitrogen sparging.

\subsubsection{Monitoring of $\mathrm{H}_{2} \mathrm{O}_{2}$ formation}

Experiments were carried out in sulphuric acid (pH 1 and $\mathrm{pH} 3$ ) with a cathode of $74.5 \mathrm{~cm}^{2}$ geometrical surface, after air sparging at $-0.5 \mathrm{~V} / \mathrm{SCE}$.

After one hour of electrolysis, the concentration of hydrogen peroxide in the solution was respectively $0.410^{-4}$ and $0.510^{-4}$ mol. $\mathrm{L}^{-1}$ for $\mathrm{pH} 1$ and $\mathrm{pH} 3$. These concentrations were similar to those obtained by Daneshvar et al. (Daneshvar et al. 2008) with a lower surface electrode $\left(7.6 \mathrm{~cm}^{2}\right)$. The authors showed that the hydrogen peroxide concentration increased with the electrode surface. Contrarily in the present work and if compared to the results of Daneshvar et al. (Daneshvar et al. 2008), the $\mathrm{H}_{2} \mathrm{O}_{2}$ formation was especially dependent on the oxygen supply which was hence the limiting factor.

\subsubsection{Influence of the operating parameters}

\section{Influence of pH and electrolyte concentration}

Concerning the Fenton reaction, an optimal $\mathrm{pH}$ value of 3 was reported in several reports (J. H. Ramirez et al. 2009; Gallard et al. 1998; Qiang et al. 2003; Panizza and Cerisola 2009; 
Zhou et al. 2007; H. J. Ramirez et al. 2005). For $\mathrm{pH}<3$, Fenton process would be less effective because ferric and ferrous ions were complexed and could not react with hydrogen peroxide. However, in electro-Fenton process, this phenomenon was compensated by the continuous regeneration of ferrous ions consequently to electro reduction of ferric ions (Rosales et al. 2009). Moreover, for $\mathrm{pH}<3$, the formation of oxonium ions $\left(\mathrm{H}_{3} \mathrm{O}_{2}{ }^{+}\right)$could limit the formation of hydroxyl radicals (Sun et al. 2009).

In the case of Biebrich Scarlett and Methyl Red, a flocculation was observed at $\mathrm{pH} 3$ due to the weak solubility of the acidic form of the two azo dyes. For $\mathrm{pH} \leq 2.35$ and $\mathrm{pH} \leq 1.5$ for BS and MR respectively, the protonation of the azo dye allowed their solubilisation. So for the electro-Fenton treatment of BS and MR solutions, experiments were also carried out at pH 1. The decolorization of $100 \mathrm{mg} . \mathrm{L}^{-1}$ orange II at various $\mathrm{pH}$ values is presented in figure 3. When the study was performed at $\mathrm{pH} 1,99 \%$ of decolorization was obtained after 16 min of treatment whereas this percentage was obtained after $140 \mathrm{~min}$ at $\mathrm{pH}$ 3. These results were not in agreement with previous study, since as previously explained; an optimal $\mathrm{pH}$ of 3 for the electro-Fenton process was reported. If the direct electrochemical reduction of Orange II at the carbon felt surface was responsible for the decolorization, this difference can be explained by a higher ionic strength of the solution for $\mathrm{pH} 1$ and hence by the improvement of mass transport by migration with the increase of the sulphuric acid concentration.

When sodium sulphate salt was added to a pH 3 solution (Fig. 3), an increase of the degradation rate was highlighted. $99 \%$ of decolorization were obtained after 50, 45 and 42 min for $0.05,0.1$ and 0.2 mol.L $\mathrm{L}^{-1} \mathrm{Na}_{2} \mathrm{SO}_{4}$, respectively; instead of 140 min without $\mathrm{Na}_{2} \mathrm{SO}_{4}$. These results were also in agreement with an electrochemical reduction of the azo dyes instead of hydroxyl radicals attack.

In the range $0.1-0.2 \mathrm{~mol} . \mathrm{L}^{-1}$, the influence of the electrolyte concentration was not really significant. It was in agreement with the previous study of Daneshvar et al. (Daneshvar et al. 
2008), who obtained an almost constant decolorization rate for $\mathrm{NaClO}_{4}$ electrolyte concentration range $0.05-0.1 \mathrm{~mol} . \mathrm{L}^{-1}$. If compared to $\mathrm{pH} 1$, the time required for a quasi total decolorization was longer at $\mathrm{pH} 3$ even in the presence of an electrolyte.

\section{Influence of the temperature}

The influence of the temperature was examined for the decolorization of $100 \mathrm{mg} . \mathrm{L}^{-1}$ solution of $\mathrm{MR}$ and a $\mathrm{pH}$ value of 1 with a potential of $-0.5 \mathrm{~V} / \mathrm{SCE}$ (Fig.4). For the three tested temperatures, 30,40 and $50^{\circ} \mathrm{C}$, the decolorization efficiencies were $80.4,97.0$ and $99.0 \%$ after 10 min of electro-Fenton treatment, respectively. An increase of the temperature led also to an increase of the decolorization efficiency for the other dyes (not shown) The temperature played a role in the electron transfer and the mass transport, and hence on the regeneration of Fe(II) (Qiang et al. 2003; E. Guivarch 2004). However, the benefit of a temperature increase at the early stage of treatment should be evaluated in light of the additional energetic cost.

However, increasing the treatment time beyond $20 \mathrm{~min}$ did not improve the decolorization efficiencies. Moreover, on the one hand a too high temperature can induce to a self decomposition of hydrogen peroxide to water and dioxygen leading to a decrease of the decolorization efficiency, and on the other hand a high temperature did not favour dioxygen solubilisation (E. Guivarch 2004).

\section{Influence of ferric ions concentration}

The influence of ferric ions concentration on the degradation of MR was studied with a potential of $-0.5 \mathrm{~V} / \mathrm{SCE}$ in $\mathrm{pH} 1$ solutions.

Five concentrations in the range $0.05-2 \mathrm{mmol.} \mathrm{L}^{-1}$ were tested and the decolourization yields after $8 \mathrm{~min}$ of treatment were in the range $88.7-92.6 \%$ respectively (Table 1). After $45 \mathrm{~min}$ of treatment and for all tested concentrations, decolorization yields were above 99\% (Table 
1), showing that the concentration of ferric ions did not significantly influence decolorization rate and efficiency. This result was not in agreement with other studies (Ozcan et al. 2009; Zhou et al. 2007). Indeed, the optimal concentration of catalyst previously reported was 0.2 mmol. $\mathrm{L}^{-1}$; while these authors observed an efficiency decrease for higher catalyst concentrations which was attributed to the following competitive reactions involving $\mathrm{Fe}^{2+}$ and $\mathrm{Fe}^{3+}$ (Ozcan et al. 2009):

$$
\mathrm{Fe}^{2+} \cdot \mathrm{OH} \rightarrow \mathrm{Fe}^{3+}+\mathrm{OH}^{-}
$$$$
\mathrm{Fe}^{3+}+\mathrm{H}_{2} \mathrm{O}_{2} \rightarrow \mathrm{Fe}-\mathrm{OOH}^{2+}+\mathrm{H}^{+}
$$

$\mathrm{Fe}-\mathrm{OOH}^{2+} \rightarrow \mathrm{Fe}^{2+}+{ }^{\bullet} \mathrm{OH}_{2}$

Further experiments without catalyst were carried out in the same operating conditions. $87.5 \%$ of MR was discoloured after 8 min of treatment and $99.6 \%$ after $45 \mathrm{~min}$. Without $\mathrm{Fe}^{2+}$ in the solution, no Fenton's reaction occurred and hence no hydroxyl radicals were produced. As seen above (paragraph 3.1.1.), at the cathodic potential of $-0.5 \mathrm{~V} / \mathrm{SCE}$, the electrochemical reduction of the azo dye on the carbon felt electrode can also be assumed.

\section{Influence of cathodic potentials}

For all tested potentials, $-0.25,-0.4$ and $-0.5 \mathrm{~V} / \mathrm{SCE}$, decolorization yield was above $99 \%$ after 30 min of treatment of a $100 \mathrm{mg} . \mathrm{L}^{-1} \mathrm{MR}$ solution (Fig. 5). A negligible effect of the cathodic potentials on the removal of azo dye was shown (Fig. 5), in agreement with a previous study (Daneshvar et al. 2008). This result was not in accordance with previous reports related to electro-Fenton processes showing an optimal potential of $-0.5 \mathrm{~V} / \mathrm{SCE}$ for the simultaneous reduction of dioxygen and ferric ions at the cathode surface (Oturan M.A. 1995; E. Guivarch et al. 2003b; Qiang et al. 2002).

Danechvar et al. (Daneshvar et al. 2008) analysed theirs results from the current potential curves plotted with $\mathrm{O}_{2}$ saturated solutions containing Orange II. From -0.5 to -1 V/SCE, a 
plateau appeared on the curve which was attributed to the reduction of dissolved dioxygen to hydrogen peroxide, and hence any potential applied in the range -0.5 to $-1 \mathrm{~V}$ during electroFenton process did not influence the production of hydrogen peroxide. Quiang et al. (Qiang et al. 2003) have reported the same conclusion concerning the attribution of peaks observed during a linear scanning voltammetry in the range -0.3 to $-0.8 \mathrm{~V} / \mathrm{SCE}$ in presence of dioxygen and methyl red (100 mg. $\left.\mathrm{L}^{-1}\right)$.

In the potential range -0.25 to $-0.5 \mathrm{~V} / \mathrm{SCE}$, all the azo dyes react at the electrode surface. From the current potential curves for all the studied dyes (paragraph 3.1.1.), all the potentials belong to the limiting current region, so no influence of potential can be observed on the decolorization of the azo dyes.

\section{Electrochemical reduction of azo dye solutions}

In the electro-Fenton process, the decolorization of MR was carried out with a ferric concentration of $0.1 \mathrm{mmol} . \mathrm{L}^{-1}$ and a cathodic potential of $-0.5 \mathrm{~V} / \mathrm{SCE}$. The $\mathrm{pH}$ was initially adjusted at 1 and the temperature was $30^{\circ} \mathrm{C}$.

Without ferric ions in the solution, the same decolorization yield as that obtained by electroFenton was achieved after 15 min, namely 99\%, which was in agreement with an electrochemical reduction of this azo dye. The same results were also observed for OR II and BS.

Figure 6 shows the UV/visible absorption spectra of a MR solution at various times during the physico-chemical treatment. In the UV region, a shoulder around $220 \mathrm{~nm}$ and a band at 290 nm were observed. These wavelength were ascribed to $\pi-\sigma-\pi$ transitions corresponding to the conjugated aromatic system. In the visible region an absorbance peak was observed at 525 $\mathrm{nm}$, which corresponded to the absorption of the $\mathrm{n}-\pi^{*}$ transition related to the $-\mathrm{N}=\mathrm{N}-$ bond. During electrolysis, the absorbance at $220 \mathrm{~nm}$ decreased slowly unlike the absorbance at 290 
$\mathrm{nm}$ and $525 \mathrm{~nm}$; the decrease of the last signal corresponded to the cleavage of the nitrogen double bond, and hence illustrated the decolorization of the solution. The peak disappeared after 20 min which was in agreement with the decolorization results. Moreover, the cleavage of the azo bond entailed a decrease of the system conjugation illustrated by a decrease of the absorbance at $290 \mathrm{~nm}$. After two hours of treatment, this last peak had also almost totally disappeared (data not shown).

Considering an electrochemical reduction of MR, the azo double bond is more reducible than most other functional group (Lund and Hammerich 2001). According to the current potential curve (Fig. 2b), the evolution of the UV/visible spectra (Fig. 6) and previous studies (Cheng and Guo 2007; Xu et al. 1996), an electrochemical reduction involving two electrons could be proposed:

\section{COD evolution}

Until 45 min of treatment, COD values remained constant for each azo dye (Table 2) which was in agreement with an electrochemical reduction of these compounds; an oxidation by hydroxyl radicals would entail a decrease of the COD values.

Beyond 45 min of treatment, i.e. beyond total decolorization, COD values decreased for each azo dye solution. After 22h, oxidation yields were $71.8,75.5$ and $33 \%$ for OR II, BS and MR, respectively.

Current potential curves plotted with electrolysed solution did not show signals on reduction (data not shown), which meant that by-products from the electrochemical reduction of azo 
dyes were not electroactive in reduction. Oxygen can be thus reduced at the cathode surface to produce hydrogen peroxide. The COD decrease could therefore be attributed to the oxidation of by-products by hydroxyl radicals produced during the Fenton reaction. Moreover, the formation of hydroxyl radicals could explain the drastic decrease of the peak at $290 \mathrm{~nm}$ after 2 $\mathrm{h}$ of MR treatment because hydroxyl radicals easily attack unsaturated bonds and then aromatics (Buxton et al. 1988).

It can be noted that $\mathrm{COD}$ determination cannot be disturbed by $\mathrm{H}_{2} \mathrm{O}_{2}$ formation because maximal concentration of hydrogen peroxide was $0.05 \mathrm{mmol} . \mathrm{L}^{-1}$, while the ferrous ions concentration was $0.1 \mathrm{mmol} . \mathrm{L}^{-1}$. Hydrogen peroxide was therefore the limiting factor and totally reacted with ferrous ions to form hydroxyl radicals.

\section{Biodegradability of the pre-treated solutions}

A solution is usually considered biodegradable when the ratio between $\mathrm{BOD}_{5}$ and $\mathrm{COD}$ is greater than 0.4. For each azo dye solution, the biodegradability was estimated initially and after 45 min of treatment for each dye, and after $28 \mathrm{~h}$ of treatment for OR II and MR, and $22 \mathrm{~h}$ for BS (Table 2).

As expected, the dyes were initially not biodegradable (Table 2). After $45 \mathrm{~min}$ of pretreatment only the biodegradability of the MR pre-treated solution seemed to increase, with a ratio $\mathrm{BOD}_{5} / \mathrm{COD}$ of 0.23 but the solution remained weakly biodegradable (Table 2). These promising results recorded after $45 \mathrm{~min}$ for MR were not confirmed if the pre-treatment lasted longer (28h), since the biodegradability tended to decrease with a final ratio of 0.14 . Oxidation of by products from the electrochemical reduction of MR seemed to entail a greater biorecalcitrance of the solution.

Pre-treated solutions of BS were not biodegradable after decolorization (45 min) and after 22h of treatment even if the biodegradabilty slightly increased after $22 \mathrm{~h}$. 
The behavior of the pre-treated OR II solution was quite different. Indeed, just after decolorization, the solution was not biodegradable $\left(\mathrm{BOD}_{5} / \mathrm{COD}=0\right)$ but if the duration of the pre-treatment increased, the solution became more easily biodegradable with a ratio $\mathrm{BOD}_{5} / \mathrm{COD}$ of 0.81 after $28 \mathrm{~h}$ of treatment.

\section{Conclusion}

The electrochemical pre-treatment of the three azo dyes namely OR II, BS and MR was a combination between an electrochemical reduction on the carbon felt cathode responsible for the decolorization of the target compounds and the electro-Fenton oxidation of their byproducts.

The study of the influence of operating parameters during electro-Fenton treatment highlighted differences with the literature which were explained after examination of the electrochemical behavior of the considered dyes. Indeed, this study highlighted the electroactivity of the three azo dyes, OR II, BS and MR. In the considered operating conditions, decolorization of the dyes was mainly due to their electrochemical reduction on the carbon felt cathode, confirmed by the absence of COD variations showing an absence of oxidation. After decolorization, by-products from the electrochemical reduction were oxidized by hydroxyl radicals produced during the Fenton reaction and a decrease of the COD value was then observed. It was also shown an absence of by-products reduction on the carbon felt and then the dioxygen reduction was favoured.

Concerning the feasibility of coupling this pre-treatment with a biological process, the results confirmed the recalcitrance of the studied azo dyes. The physico chemical treatment allowed an increase of the biodegradability except for BS. In the case of MR, the decolorization of the solution enhanced the biodegradability, but the subsequent oxidation of the by-products did 
not favor this tendency. On the contrary, an electrochemical reduction of OR II leading to a decolorization followed by an oxidation of the by-products with the hydroxyl radicals resulting from the Fenton reaction provided an easily biodegradable solution with a ratio $\mathrm{BOD}_{5} / \mathrm{COD}$ of 0.81 after $28 \mathrm{~h}$ of treatment. 
References

Arslan, I., Bacioglou, I. A., Tuhkanen, T., \& Bahnemann, D. (2000). H2O2/UV-C and $\mathrm{Fe} 2+/ \mathrm{H2O} / \mathrm{UV}-\mathrm{C}$ versus TiO2/UV-A treatment for reactive dye wastewater. $J$. Environ. Eng., 126, 903-911.

Auriol, M., Filali-Meknassi, Y., Tyagi, R. D., \& Adams, C. D. (2006). Endocrine disrupting compounds removal from wastewater, a new challenge. Process Biochem., 41, 525-539.

Borras, N., Arias, C., Oliver, R., \& Brillas, E. (2011). Mineralization of desmetryne by electrochemical advanced oxidation processes using a boron-doped diamond anode and an oxygen-diffusion cathode. Chemosphere, 85, 1167-1175.

Brillas, E., Sirés, I., \& Oturan, M. A. (2009). Electro-Fenton process and related electrochemical technologies based on Fenton's reaction chemistry. Chem. Rev., $109,6570-6631$.

Brown, M. A., \& De Vito, S. C. (1993). Predicting azo dye toxicity. Crit. Rev. Env. Sci. Technol., 23, 249-324.

Buxton, G. U., Greenstock, C. L., Helman, W. P., \& Ross, A. B. (1988). Critical review of rate constant for reactions of hydrated electrons, hydrogen atoms and hydroxyl radicals $\left(\mathrm{HO}^{\circ} / \mathrm{O}^{\circ}\right)$. J. Phys. Chem., 17(2), 513-759.

Chaudhuri, S. K., \& Sur, B. (2000). Oxidative decolorization of reactive dye solution using fly ash as catalyst. J. Environ. Eng., 126, 583-594.

Chebli, D., Fourcade, F., Brosillon, S., Nacef, S., \& Amrane, A. (2010). Supported photocatalysis as a pre-treatment prior to biological degradation for the removal of some dyes from aqueous solutions; Acide Red 183, Biebrich Scarlet, Methyl Red Sodium Salt, Orange II. J. Chem. Technol. Biotechnol., 85(4), 555-563. 
Cheng, X. H., \& Guo, W. (2007). The oxidation kinetics of reduction intermediate product of methyl red with hydrogen peroxide. Dyes Pigm., 72, 372-377.

Chiron, S., Fernadez-Alba, A., Rodriguez, A., \& Garcia-Calvo, E. (2000). Pesticide chemical oxidation: state of the art. Water Res., 34(2), 366-377.

Comninellis, C., Kapalka, A., Malato, M., Parsons, S. A., Poulios, I., \& Mantzavinos, D. (2008). Perspective Advanced Oxidation Processes for water treatment: advances and trends for R\&D. J. Chem. Technol. Biotechnol., 83, 769-776.

Cruz-Gonzales, K., Torres-Lopez, O., Garcia-Leon, A. M., Brillas, E., HernandezRamirez, A., \& Peralta-Hernandez, J. M. (2012). Optimization of electroFenton/BDD process for decolorization of a model azo dye wastewater by means of response surface methodology. Desalination, 286, 63-68.

Daneshvar, N., Aber, S., Vatanpour, V., \& Rasoulifard, M. H. (2008). Electro-Fenton treatment of dye solution containing Orange II: influence of operational parameters. J. Electroanal. Chem., 615(2), 165-174.

De La Rochebrochard D'Auzay, S., Brosillon, S., Fourcade, F., \& Amrane, A. (2007). Integrated process for degradation of amitrole in wastewaters: photocatalysis/biodegradation. Int. J. Chem. React. Eng., 5, A51.

Dominguez, J. R., Beltran, J., \& Rodriguez, O. (2005). Vis and UV photocatalytic detoxification methods (using $\mathrm{TiO}_{2}, \mathrm{TiO}_{2} / \mathrm{H}_{2} \mathrm{O}_{2}, \mathrm{TiO}_{2} / \mathrm{S}_{2} \mathrm{O}_{8}{ }^{2-}, \mathrm{O}_{3}, \mathrm{H}_{2} \mathrm{O}_{2}, \mathrm{~S}_{2} \mathrm{O}_{8}{ }^{2-}$, $\mathrm{Fe}^{3+} / \mathrm{H}_{2} \mathrm{O}_{2}$, and $\mathrm{Fe}^{3+} / \mathrm{H}_{2} \mathrm{O}_{2} / \mathrm{C}_{2} \mathrm{O}_{4}{ }^{2-}$ ) for dyes treatment. Catal. Today, 101, 389-395.

Forgacs, E., Cserhati, T., \& Oros, G. (2004). Removal of synthetic dye from wastewater: a review. Environ. Int., 30, 953-971.

Gallard, H., De Laat, J., \& Legube, B. (1998). Influence du pH sur la vitesse d'oxydation de composés organiques par $\mathrm{Fe}(\mathrm{II}) / \mathrm{H}_{2} \mathrm{O}_{2}$. Mécanismes réactionnel et modélisation. New J. Chem., 2(3), 263-268. 
Guivarch, E. (2004). Traitement des polluants organiques en milieux aqueux par procédé électrochimique d'oxydation avancée "Electro-Fenton". Application à la minéralisation des colorants synthétiques: PhD thesis, Université Marne la Vallée, France.

Guivarch, E., Oturan, N., \& Oturan, M. A. (2003a). Removal of organophosphorus pesticides from water by electrogenerated Fenton's reagent. Environ. Chem. Lett., $1,165-168$.

Guivarch, E., Trevin, S., Lahitte, C., \& Oturan, M. A. (2003b). Degradation of azo dyes in water by electro-Fenton process. Environ. Chem. Lett., 1, 38-44.

Hachem, C., Bocquillon, F., Zahraa, O., \& Bouchy, M. (2001). Decolourization of textile industry wastewater by the photocatalytic degradation process. Dyes Pigm., 49, 117-125.

Hammami, S., Bellakhal, N., Oturan, N., Oturan, M. A., \& Dachraoui, M. (2008). Degradation of Acid Orange 7 by electrochemically generated OH radicals in acidic aquous medium using a boron-doped diamond or platinuim anode: a mechanistic study. Chemosphere, 73, 678-684.

Ledakowicz, S., Solecka, M., \& Zylla, R. (2001). Biodegradation, decolourisation and detoxification of textile wastewater enhanced by advanced Oxidation Processes. J. Biotechnol., 89, 175-184.

Lund, H., \& Hammerich, O. (2001). Organic electrochemistry, Four edition. New York: Marcel Decker, INC.

Oller, I., Malato, S., \& Sanchez-Perez, J. A. (2011). Combination of Advanced Oxidation Processes and biological treatments for wastewater decontamination-A review. Sci. Total Environ., 409, 4141-4166. 
Oppenländer, T. (2003). Photochemical purification of water and air advanced oxidation processes (AOPs): principles, reactions mechanisms, reactor concepts. London: Wiley-VCH.

Oturan M.A., P. J. (1995). Hydroxylation by electrochemically generated OH radicals. Mono- and polyhydroxylation of benzoic acid: products and isomer's distribution. J. Phys. Chem., 99, 13948-13954.

Ozcan, A., Oturan, M. A., Oturan, N., \& Sahin, Y. (2009). Removal of Acid Orange 7 from water by electrochemically generated Fenton's reagent. J. Hazard. Mater., 163(2-3), 1213-1220.

Ozcan, A., Sahin, Y., Koparal, A. S., \& Oturan, M. A. (2008). Carbon sponge as a new cathode material for the electro-Fenton process: comparison with carbon felt cathode and application to degradation od synthetic dye Basic Blue 3 in aqueous medium. J. Electroanal. Chem., 616, 71-78.

Panizza, M., \& Cerisola, G. (2009). Electro-Fenton degradation of synthetic dyes. Water Res., 43, 339-344.

Poyatos, J. M., Munio, M. M., Almecija, M. C., Torres, J. C., Hontorio, E., \& Osorio, F. (2010). Advanced oxidation processes for wastewater treatment: state of the art. Water Air Soil Pollut., 205(1-4), 187-204.

Qiang, Z., Chang, J. H., \& Huang, C. P. (2002). Electrochemical generation of hydrogen peroxide from dissolved oxygen in acidic solutions. Water Res., 36, 85-94.

Qiang, Z., Chang, J. H., \& Huang, C. P. (2003). Electrochemical generation of $\mathrm{Fe}^{2+}$ in Fenton oxidation processes. Water Res., 37(6), 1308-1319.

Ramirez, H. J., Costa, C. A., \& Madeira, L. M. (2005). Experimental design to optimize the degradation of the synthetic dye Orange II using Fenton's reagent. Catal. Today, 107-108, 68-76. 
Ramirez, J. H., Duarte, F. M., Martins, F. G., Costa, C. A., \& Madeira, L. M. (2009). Modelling of the synthetic dye Orange II degradation using Fenton's reagent: from batch to continuous reactor operation. Chem. Eng. J., 148, 394-404.

Robinson, T., McMullan, G., Marchand, R., \& Nigam, P. (2001). Remediation of dyes in textile effluent: a critical review on current treatment technologies with a proposed alternative. Bioresour. Technol., 77, 247-255.

Rosales, E., Pazos, M., Longo, M. A., \& Sanroman, M. A. (2009). Electro-Fenton decoloration of dyes in continuous reactoir: a promising technology in colored wastewater treatment. Chem. Eng. J., 155(1-2), 62-67.

Scott, J. P., \& Ollis, D. F. (1995). Integration of chemical and biological processes for water treatment: review and recommendations. Environ. Prog., 14, 88-103.

Scott, J. P., \& Ollis, D. F. (1997). Integration of chemical and biological oxidation processes for water treatment: II. recent illustrations and experiences. J. Adv. Oxid. Technol., 2, 374-381.

Sires, I., Guivarch, E., Oturan, N., \& Oturan, M. A. (2008). Efficient removal of triphenylmethane dyes from aqueous medium by in situ electrogenerated Fenton's reagent at carbon-felt electrode. Chemosphere, 72, 592-600.

Stock, N. L., Peller, J., Vinodgopal, K., \& Kamat, P. V. (2000). Combinative sonolysis and photocatalysis for textile dye degradation. Environ. Sci. Technol., 34, 17471750.

Sun, S. P., Li, C. J., Sun, J. H., Shib, S. H., Fand, M. H., \& Zhoua, Q. (2009). Decoloration of an azo dye Orange $G$ in aqueous solution by Fenton oxidation process: effect of system parameters and kinetic study. J. Hazard. Mater., 161, 1052-1057. 
Tantak, N. P., \& Chaudhari, S. (2006). Degradation of azo dyes by sequential Fenton's oxidation and aerobic biological treatment. J. Hazard. Mater., 136(6), 698-705.

Wang, A., Qu, J., Ru, J., Liu, H., \& Ge, J. (2005). Mineralization of an azo-dye Acide Red 14 by electro-Fenton's reagent using an activated carbon fiber cathode. Dyes Pigm., 65, 227-233.

Xu, G., O'Dea, J. J., \& Osteryoung, J. G. (1996). Surface reduction study of monoazo dyes by adsorptive square wave voltammetry. Dyes Pigm., 30(3), 201-223.

Zhou, M., Yu, Q., Lei, L., \& Barton, G. (2007). Electro-Fenton method for the removal of Methyl Red in an efficient electrochemical system. Sep. Purif. Technol., 57(2), 380-387. 
Table 1. MR (100 mg. $\mathrm{L}^{-1}$ ) decolorization yields recorded during electro-Fenton experiments on a graphite felt electrode of $74.5 \mathrm{~cm}^{2}$ surface at a potential of $-0.5 \mathrm{~V} / \mathrm{ECS}$, at $\mathrm{T}=30^{\circ} \mathrm{C}$, in $\mathrm{H}_{2} \mathrm{SO}_{4} \mathrm{pH} 1$ for various initial ferrous ion concentrations

\begin{tabular}{ccccccc}
\hline & \multicolumn{5}{c}{ Decolorization yield (\%) } \\
\cline { 2 - 7 } & 0 & 0.05 & 0.1 & 0.5 & 1 & 2 \\
\hline 8 min & 87.5 & 91.0 & 92.6 & 91.9 & 89.9 & 88.7 \\
45 min & 99.6 & 99.3 & 99.5 & 99.7 & 99.9 & 99.9 \\
\hline
\end{tabular}

Table 2. Parameters values collected during azo dyes treatments

\begin{tabular}{|c|c|c|c|c|c|}
\hline & & & Orange II & Methyl Red & Biebrich Scarlet \\
\hline $\begin{array}{c}\text { Working } \\
\text { wavelength }\end{array}$ & $\mathrm{nm}$ & & 484 & 466 & 506 \\
\hline \multirow[t]{3}{*}{ COD } & $\left(\mathrm{mg} \mathrm{O}_{2} \mathrm{~L}^{-1}\right)$ & initial & 142 & 144 & 106 \\
\hline & & $45 \mathrm{~min}$ & 144 & 140 & 104 \\
\hline & & Final* & 29 & 90 & 26 \\
\hline \multirow[t]{3}{*}{$\mathrm{BOD}_{5} / \mathrm{COD}$} & & initial & 0 & 0 & 0 \\
\hline & & $45 \mathrm{~min}$ & 0 & 0.23 & 0 \\
\hline & & Final* & 0.81 & 0.14 & 0.10 \\
\hline
\end{tabular}

$* \mathrm{t}=28 \mathrm{~h}$ for OR II and MR, $\mathrm{t}=22 \mathrm{~h}$ for BS 


\section{Figure legends}

Fig.1. Chemical structure of the used azo-dyes; (A) Orange II, (B) Methyl red, (C) Biebrich Scarlet.

Fig.2. Current-potential curve obtained with a vitreous carbon rotating electrode $\left(\mathrm{S}=3.210^{-2}\right.$ $\mathrm{cm}^{2}$ and $\left.2500 \mathrm{rpm}\right), \mathrm{r}=5 \mathrm{mV} . \mathrm{s}^{-1}$, under nitrogen atmosphere and $\mathrm{T}=298 \mathrm{~K}$, for OR II (100 $\left.\mathrm{mg} \mathrm{L}^{-1}\right)(\mathrm{A}), \mathrm{MR}\left(100 \mathrm{mg} \mathrm{L}^{-1}\right)(\mathrm{B})$ and $\mathrm{BS}\left(100 \mathrm{mg} \mathrm{L}^{-1}\right)(\mathrm{C})$, in $\mathrm{H}_{2} \mathrm{SO}_{4} \mathrm{pH} 3$ and $\mathrm{Na}_{2} \mathrm{SO}_{4} 0.1$ mol. $\mathrm{L}^{-1}$ for (A) and in $\mathrm{H}_{2} \mathrm{SO}_{4} \mathrm{pH} 1$ for (B) and (C).

Fig.3. Time-courses of OR II (100 mg. $\left.\mathrm{L}^{-1}\right)$ decolorization yields recorded during electroFenton experiments on graphite felt electrode of $74.5 \mathrm{~cm}^{2}$ surface at a potential of -0.5 V/ECS, with 0.1 mmol.L $\mathrm{L}^{-1} \mathrm{Fe}^{3+}$, at $\mathrm{pH} 1$ and 3 and for various $\mathrm{Na}_{2} \mathrm{SO}_{4}$ concentrations.

Fig.4. Time-courses of MR (100 mg. $\left.\mathrm{L}^{-1}\right)$ decolorization yields recorded during electro-Fenton experiments on a graphite felt electrode of $74.5 \mathrm{~cm}^{2}$ surface at a potential of $-0.5 \mathrm{~V} / \mathrm{ECS}$, with 1 mmol. $\mathrm{L}^{-1} \mathrm{Fe}^{3+}$, at $\mathrm{pH} 1$ for various temperatures

Fig.5. Time-courses of MR (100 mg. $\left.\mathrm{L}^{-1}\right)$ decolorization yields recorded during electro-Fenton experiments on a graphite felt electrode of $74.5 \mathrm{~cm}^{2}$ surface with $0.1 \mathrm{mmol} . \mathrm{L}^{-1} \mathrm{Fe}^{3+}$ at $\mathrm{pH}$, ambient temperature and for various cathodic potentials.

Fig.6. Full UV/visible spectra scanning at various running times during electrochemical treatment of MR (100 mg.L $\left.\mathrm{L}^{-1}\right)$. Experiments carried out on graphite felt electrode of $74.5 \mathrm{~cm}^{2}$ surface, at $-0.5 \mathrm{~V} / \mathrm{ECS}$, with $\left[\mathrm{Fe}^{3+}\right]=0.1 \mathrm{mmol} . \mathrm{L}^{-1}, \mathrm{~T}=30^{\circ} \mathrm{C}$, in $\mathrm{H}_{2} \mathrm{SO}_{4} \mathrm{pH} 1$. 
Figures

Figure 1A:<smiles>O=S(=O)(O[Na])c1ccc(N=Nc2c(O)ccc3ccccc23)cc1</smiles>

Figure 1B:<smiles>CN(C)c1ccc(/N=N/c2ccccc2C(=O)O[Na])cc1</smiles>

Figure 1C:

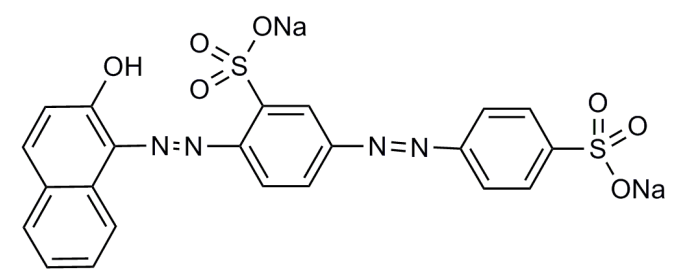

Figure 2A:

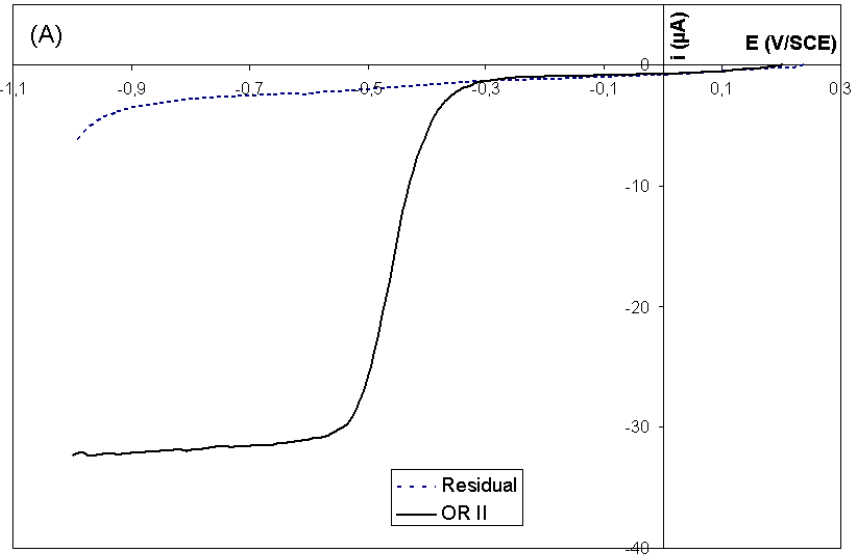


Figure 2B

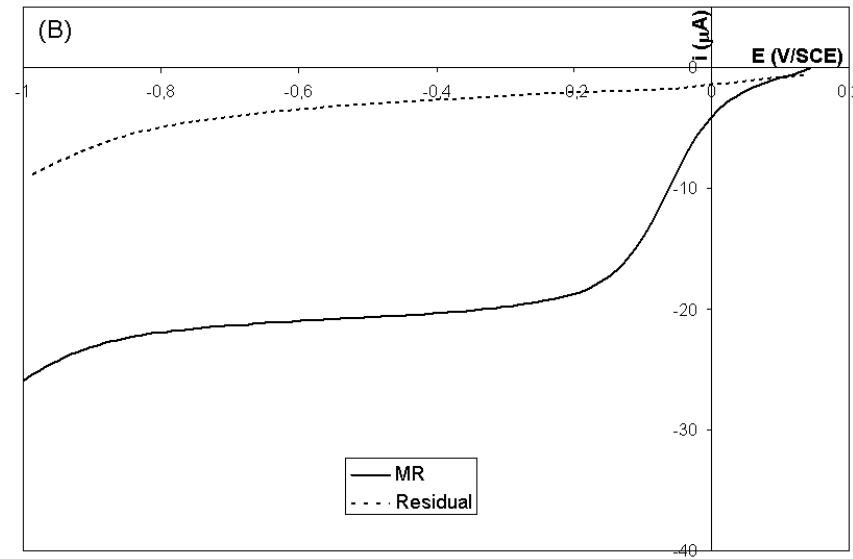

Figure 2C:

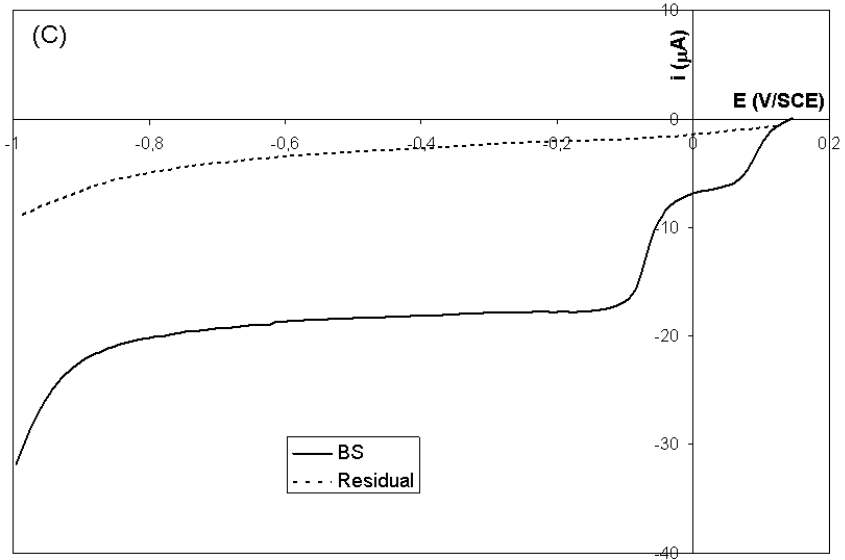


Figure 3:

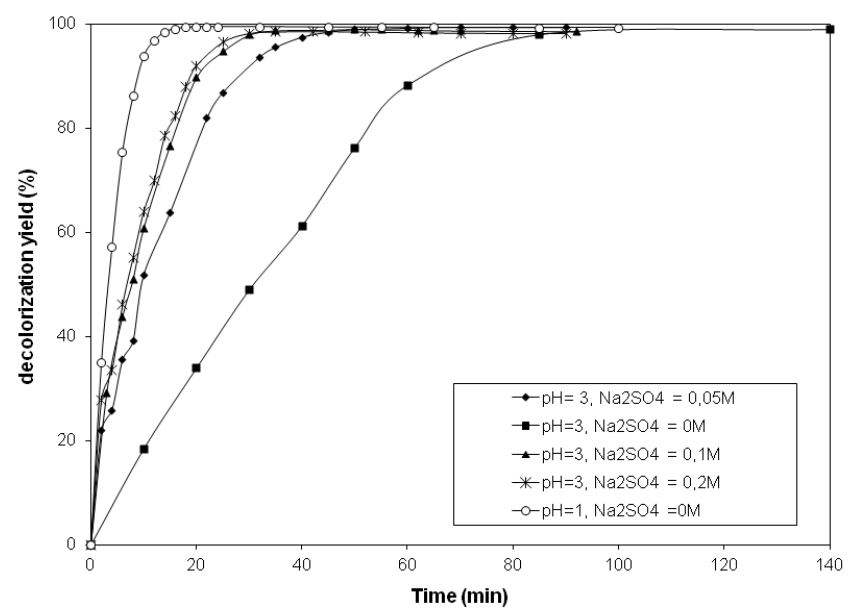

Figure 4:

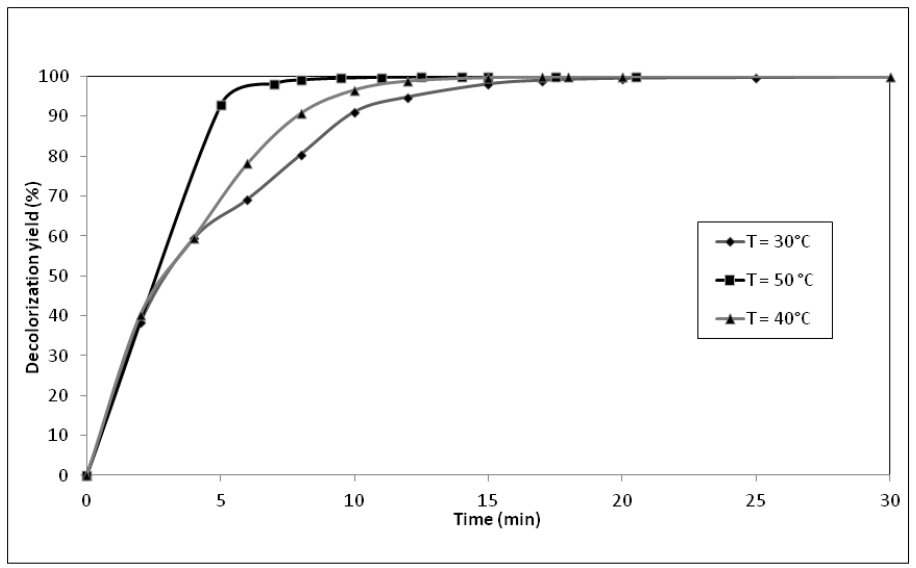


Figure 5:

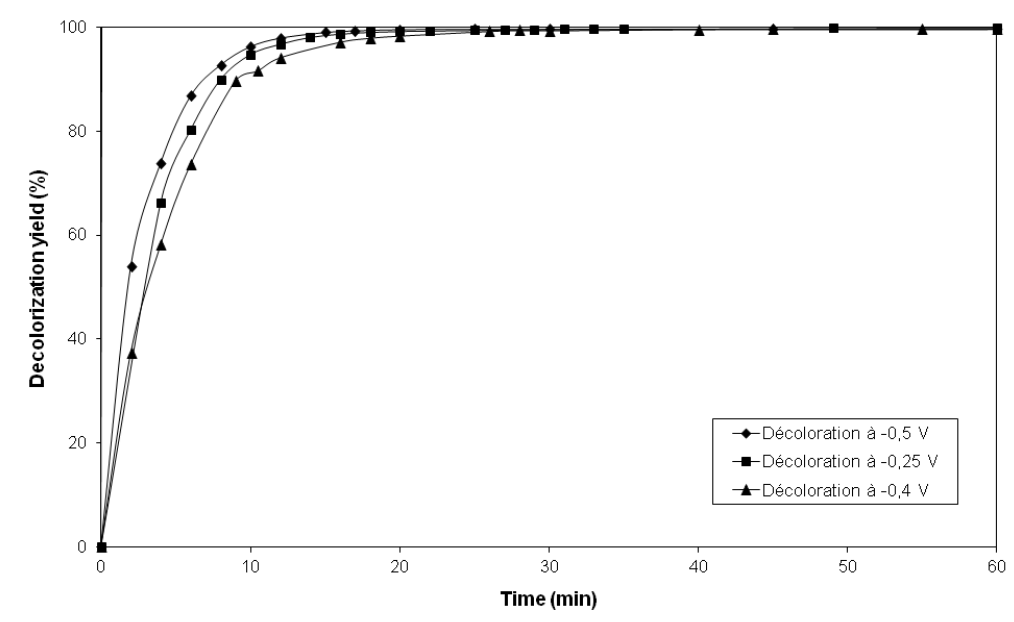

Figure 6

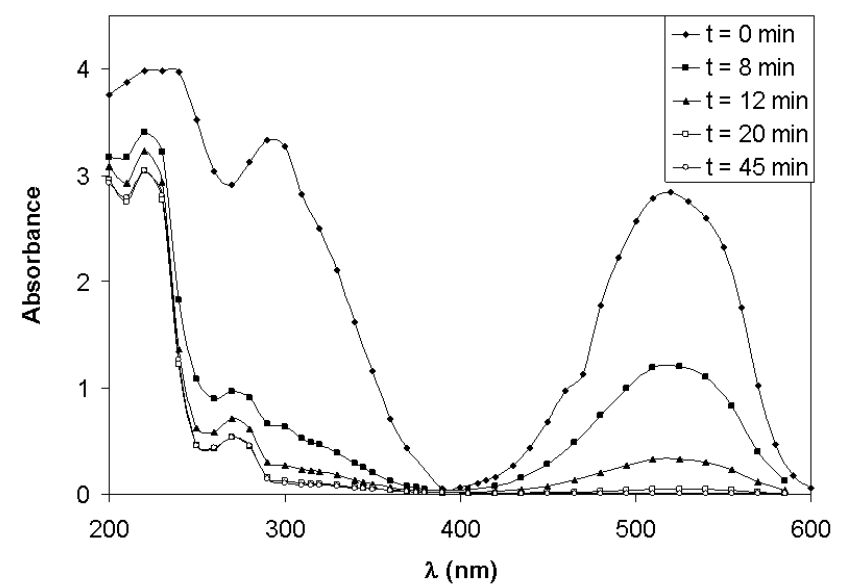

